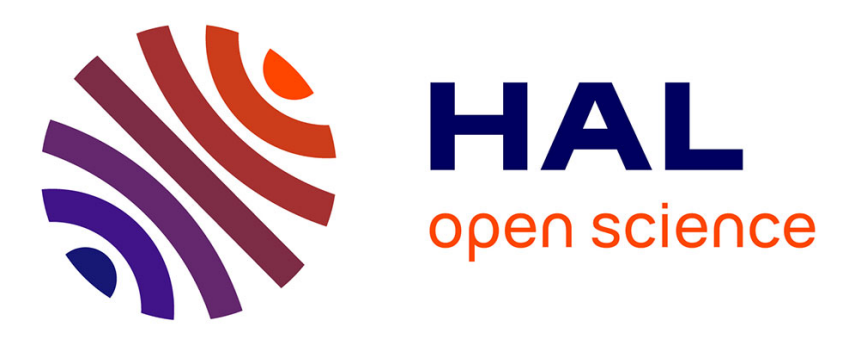

\title{
The magical orbitofrontal cortex.
}

Geoffrey Schoenbaum, Mehdi Khamassi, Mathias Pessiglione, Jay A

Gottfried, Elisabeth A Murray

\section{To cite this version:}

Geoffrey Schoenbaum, Mehdi Khamassi, Mathias Pessiglione, Jay A Gottfried, Elisabeth A Murray. The magical orbitofrontal cortex.. Behavioral Neuroscience, 2021, 135 (2), pp.108 - 108. 10.1037/bne0000470 . hal-03251587

\section{HAL Id: hal-03251587 https://hal.sorbonne-universite.fr/hal-03251587}

Submitted on 7 Jun 2021

HAL is a multi-disciplinary open access archive for the deposit and dissemination of scientific research documents, whether they are published or not. The documents may come from teaching and research institutions in France or abroad, or from public or private research centers.
L'archive ouverte pluridisciplinaire HAL, est destinée au dépôt et à la diffusion de documents scientifiques de niveau recherche, publiés ou non, émanant des établissements d'enseignement et de recherche français ou étrangers, des laboratoires publics ou privés. 


\title{
INTRODUCTION
}

\section{The Magical Orbitofrontal Cortex}

\author{
Geoffrey Schoenbaum $^{1}$, Mehdi Khamassi ${ }^{2}$, Mathias Pessiglione ${ }^{3}$, Jay A. Gottfried ${ }^{4}$, and Elisabeth A. Murray ${ }^{5}$ \\ 1 Intramural Research Program, National Institute on Drug Abuse \\ ${ }^{2}$ Institute of Intelligent Systems and Robotics, Sorbonne Université \\ ${ }^{3}$ Paris Brain Institute (ICM), Groupe Hospitalier Pitié-Salpêtrière, Sorbonne Université \\ ${ }^{4}$ Departments of Neurology and Psychology, University of Pennsylvania \\ ${ }^{5}$ Laboratory of Neuropsychology, National Institute of Mental Health
}

In 1987, Dr. Goldman-Rakic (1987) described the circuitry of the primate prefrontal cortex and its role in regulating behavior. This landmark work contained less than one page of material about the orbitofrontal subdivision of the prefrontal cortex, and only nine articles published that year included the term "orbitofrontal." Indeed, the first attempts to gather the ideas in a special issue at that time was titled "The Mysterious Orbitofrontal Cortex" (Schultz \& Cavada, 2000). From this inauspicious beginning, our knowledge regarding orbitofrontal function has grown exponentially; last year there were 714 articles published containing the term "orbitofrontal," and our understanding of this broad swath of cortex has arguably come to eclipse that of any other prefrontal region.

The explosive interest in the orbitofrontal function and the corresponding advance in our understanding reflects many factors, but key among them is the central role the orbitofrontal cortex plays in so many brain pathologies; orbitofrontal dysfunction has now been implicated in most major neuropsychiatric disorders that feature maladaptive or abnormal decision-making. This remarkable fact speaks to the subtle yet ubiquitous nature of the functions now being ascribed to this area. Additionally, the field has evolved a tradition of advancing principled and highly testable hypotheses to explain orbitofrontal functions, which aim to be independent of the idiosyncratic features of any particular approach. This tradition has fostered friendly interactions between groups in testing different proposals.

This tradition of advancing strong hypotheses can be seen in early work, which hypothesized a critical role for the orbitofrontal cortex

Editor's Note. This is an introduction to the "Special Issue: The Magical Orbitofrontal Cortex." Please see the Table of Contents here: http://psycnet .apa.org/journals/BNE/135/2/.—GS

Geoffrey Schoenbaum (D) https://orcid.org/0000-0001-8180-0701

Correspondence concerning this article should be addressed to Geoffrey Schoenbaum, Intramural Research Program, National Institute on Drug Abuse, 251 Bayview Blvd, Baltimore, MD 21224, United States. Email: geoffrey.schoenbaum@nih.gov in adaptive or flexible responding due to an involvement in response inhibition, associative learning, and the mobilization of internal states. Current ideas can be directly traced from this lineage and define a key role for the orbitofrontal cortex in model-based behavioral guidance, inferential reasoning, and even cognitive mapping. These themes are each well-represented in the current volume, along with the latest trends, which include an increasing focus on the discrete functions of subdivisions within the orbitofrontal cortex as well as on the role these subdivisions play within broader circuits.

This special issue, commissioned after the 4th Quadrennial Meeting on Orbitofrontal Cortex Function held in Paris in November of 2019 (https://ofc2019.sciencesconf.org/), is intended to provide a snapshot of this ongoing transformation; we hope that the ideas presented herein will provide a foundation for the next stage in the evolution of our understanding of this magical brain region.

\section{References}

Goldman-Rakic, P. S. (1987). Circuitry of primate prefrontal cortex and regulation of behavior by representational memory. In V. B. Mountcastle, F. Plum, \& S. R. Geiger (Eds.), Handbook of physiology: Vol. V. The nervous system (pp. 373-417). American Physiology Society.

Schultz, W., \& Cavada, C. (2000). The mysterious orbitofrontal cortex. Cerebral Cortex, 10, 206-219.

Received March 2, 2021

\footnotetext{
${ }^{1}$ Numbers of published articles including the term "orbitofrontal" were obtained from searches on PubMed in September 2007 and again in February 2021; note that PubMed adds articles over time, thus the numbers for past years may change marginally as additional articles are indexed.
} 